\title{
Phenotypic Preference in Mexican Migrants: Evidence from a Random Household Survey
}

\author{
Rosario Aguilar • D. Alex Hughes • Micah \\ Gell-Redman
}

Received: date / Accepted: date

\begin{abstract}
Does pre-existing preference based on skin tone, facial features, and other observable characteristics, i.e., phenotypic preference, affect immigrant voters' support for political candidates competing in their countries of origin? Do these preferences change as migrants's tenure in their host society increases? These question are important for ethnic and racial politics in general, and particularly for the sizable foreign-born population in the United States, which includes 11 million Mexicans. Using a unique, random sample of foreign-born Mexicans in San Diego County, we employ a voting experiment to test the impact of skin tone and phenotype on vote choice among first generation immigrants. Our design allows us to distinguish responses to different phenotypic cues by exposing respondents to European, mestizo and indigenous looking candidates competing in a hypothetical Mexican election. Migrants showed higher support for the Indigenous candidate, and evaluated the European and Mestizo candidates as more ideologically conservative. As migrants' time in the United States increases, the preference for indigenous features gives way to a preference for whiteness, which we interpret as evidence of first generation migrants adopting the dominant racial ideology of the United States. While ethnic distinctions have long been viewed as a key component of voting behavior, our research demonstrates that, even within a single ethnicity, racial differences may have profound impacts on the evaluation of and support for electoral candidates. This study contributes to the research
\end{abstract}

This work was supported by grants from the AVINA Foundation and the University of Arizona's Borders Program, whom the authors gratefully acknowledge. Replication materials are available at http://dx.doi.org/10.7910/DVN/2PAZJX.

Rosario Aguilar

CIDE, Centro de Investigación y Docencia Económicas, AC

E-mail: rosario.aguilar@cide.edu

D. Alex Hughes

School of Information, University of California, Berkeley

E-mail: d.alex.hughes@ischool.berkeley.edu

Micah Gell-Redman

Department of International Affairs and Department of Health Policy \& Management, University of Georgia

E-mail: mgredman@uga.edu 
on race and political behavior in comparative perspective, as well as the political consequences of migration.

Keywords Immigrant incorporation - Candidate selection P Phenotypic prejudice ·

Stereotypes · Racial politics · Voting behavior 
Does phenotypic prejudice, or pre-existing preferences based on skin tone, facial features, and other observable characteristics, affect the way immigrant voters evaluate political candidates competing in their country of origin? A broad range of scholarship suggests that the physical features that denote race shape voters' evaluation of electoral candidates 11 While it is generally accepted that physical features matter, much remains to be learned about how racial stereotypes impact candidate support and evaluation when the voter and the candidate share the same ethnic identity. We explore this question by focusing on first generation Mexican immigrants' attitudes towards Mexican politicians. Our theoretical framework borrows extensively from the literature on race and politics both in the U.S. and in comparative perspective to develop and test a theory of migrants' electoral behavior. The source of our data is a face-to-face, random household survey of first generation Mexican immigrants in San Diego County. Our research design leverages an embedded survey-experiment to test the effect of hypothetical candidates' racial appearance on vote choice and candidate evaluation.

Our results provide further evidence that stereotypes based on racial phenotypes are important cues for voters evaluating coethnic candidates. Mexican immigrants showed higher levels of support for an indigenous-looking, as opposed to a mixed (mestizo) or white-looking candidate ${ }^{2}$ We propose that this result hinges on existing stereotypes that link phenotype to social class in Mexico. In this framework, phenotype signals shared interests with first generation immigrants, who are generally of low socio-economic status. This argument concords with our second main finding, that migrants viewed the indigenous candidate as being more ideologically liberal than a white or mestizo candidate.

We also contribute more generally to the literature on the effect of immigrant's tenure in a host society on their political behavior. While we find an overall preference for indigenous appearance, this preference fades as migrants spend time in the United States. Using cross sectional evidence, we show that first generation immigrants who have spent more time in the United States are more likely to support a white candidate. We interpret this as suggestive evidence that migrants gradually adopt the dominant racial ideology of the receiving country.

\section{Stereotypes, race, and electoral choice}

In order to make sense of the world and react quickly to outside stimuli, people categorize individuals and things into groups and attribute characteristics to those groups for use in future interactions (Smith and Medin, 1981). While this exercise may be useful in certain circumstances, some of the information individuals associate with the resulting categories may be stereotypical. Stereotypes are cognitive structures "consisting of a category label and its corresponding traits" attached to members of social groups (Berinsky and Mendelberg, 2005). A particularly important class of stereotypes are beliefs about attitudes, behaviors, and other characteristics of groups based on race and ethnicity.

${ }^{1}$ For a general approach to the use of physical features in forming opinions about others, see Ashmore and del Boca (1981); Fiske and Taylor (1984); for specific applications to evaluations of political candidates, see Terkildsen (1993); Maddox (2004); Kam (2007); McConnaughy et al. (2010); Weaver (2012); Aguilar (2015)

${ }^{2}$ In what follows, we drop the term "looking" from our descriptions of candidate appearance. 
Stereotypes may lead people to ignore individual differences, and focus instead on generalizations about groups that have limited empirical support (Allport, 1954, Karlins, Coffman and Walters, 1969, Von Hippel, Sekaquaptewa and Vargas, 1997). These dangers notwithstanding, stereotypes influence a wide range of human behavior. Evidence from U.S. elections suggests voters rely on a candidate's race as a "low-information shortcut". In other words, racial stereotypes may be used in the same way as demographic characteristics or partisan identification to infer a candidate's ideological position and competence (Kam, 2007, Popkin, 1991, Sanbonmatsu, 2002).

Indeed, a broad spectrum of evidence demonstrates that stereotypes related to race and ethnicity shape the way voters respond to political candidates. Much of this work focuses on effects of racial prejudice between groups. For example, non-Hispanic white Americans are less likely to vote for black candidates and tend to evaluate them more negatively than white candidates (e.g., Moskowitz and Stroh, 1994, Reeves, 1997, Sears, Citrin and Kosterman, 1987, Terkildsen, 1993). This prejudicial effect is stronger against dark-skinned African American candidates (Callghan and Terkildsen, 2002, Terkildsen, 1993). Nevertheless, other studies have found no effect of race on whites' electoral choices, or an effect of skin tone rather than race per se (Colleau et al., 1990, Highton, 2004, Sigelman et al. 1995. Weaver, 2012). Implicit and explicit attitudes may influence non-Hispanic whites' evaluation of Latino candidates, but this effect disappears when controlling for partisanship (Kam, 2007).

Researchers have also examined the impact of candidate appearance among coethnics (those who identify as belonging to the same racial/ethnic group). Using observational methods, scholars have shown that Latinos turn out at higher rates when a co-ethnic is on the ballot (Barreto, 2007, Graves and Lee, 2000, Juenke, 2014). Latino immigrants who are eligible to vote do so at higher rates than nativeborn Latinos (Barreto, 2005) and tend to support Latino candidates regardless of racial appearance, as long as they are they are not of low quality (Manzano and Sanchez, 2010). However, experimental studies find either that Latinos do not necessarily show higher support for co-ethnic candidates (McConnaughy et al., 2010), or that factors such as candidate quality and partisanship are more important than ethnicity (Kam, 2007).

Studies that expose voters to different candidate profiles face a challenge, however, because racial/ethnic differences may be confounded by other traits that could impact candidate evaluation. To address this possibility, Adida, Davenport and McClendon (2016) vary the perceived ethnic membership of a single Congressman, Charles Rangel, who is of both black and Latino heritage. Among African Americans, co-ethnicity caused higher average levels of candidate support. For Latinos, however, co-ethnicity increased support only among those who perceived discrimination as a problem for their group.

The finding that co-ethnicity affected some Latinos but not others suggests that stereotypes influence behavior not only through a binary in-group/out-group distinction. Even within ethnic groups, stereotypes associated with particular traits may influence candidate support. One such trait could be racial phenotypes, which vary within ethnicity. Research in Mexico City shows that when choosing among ethnic Mexicans, voters support white candidates over mestizo or indigenous candidates (Aguilar, 2009, 2011). Observationally, racial phenotypes predict social position and political attitudes. For example, darker and indigenous-looking Mex- 
icans have lower educational attainment on average (Flores and Telles, 2012), are poorer conditional on their level of education (Villarreal |2010), and report higher levels of discrimination (Canache et al. 2014). Other research shows the existence of discrimination based on racial phenotypes in everyday language (Sue and Golash-Boza, 2013) and the persistence of positive stereotypes associated with European heritage and negative stereotypes associated with indigenous heritage (Doremus, 2001, Knight, 1990).

These findings across contexts suggest that stereotypes in general, and racial phenotypes in particular do more than simply influence which candidate a voter will support. They also act as cues for traits, including competency, leadership, empathy, and integrity, that voters typically use to evaluate political candidates (Kinder, 1986). In the U.S., whites tend to give more negative evaluations on these traits to dark-skinned African American candidates than to light-skinned African American and white candidates (Callghan and Terkildsen, 2002). Whites also use racial stereotypes about black candidates to infer partisan affiliation and ideology (Callghan and Terkildsen, 2002), and generally view black politicians as more liberal than whites (Berinsky and Mendelberg, 2005). While most African Americans identify with the Democratic Party, a binary racial classification is a blunt predictor of ideology, and many blacks are indistinguishable from white Republicans on social issues (Tate, 1994). Skin tone works as a sharpening cue for black conservative Democrats, who ascribe more socially conservative positions to dark-skinned African American politicians than to light-skinned ones (Lerman, McCabe and Sadin, 2015).

In Mexico, survey evidence shows that both social class and race are associated with political traits. Specifically, social class is correlated with ideological position on economic policy, and skin tone is predictive of partisanship (Moreno, 2009). The latter finding is particularly instructive. Those who identified with the conservative party were coded by interviewers as being lighter-skinned than those who identified with the center and left-wing parties (Moreno, 2009). While not a direct demonstration of the use of stereotypes, the evidence suggests that in this context group categorization based on race may be a powerful shortcut for inferring political traits.

Since Mexico's transition to democracy, research on voting behavior has examined partisanship (Domínguez and Lawson, 2004 Domínguez, Lawson and Moreno, 2009, Klesner, 2002, 2005), electoral campaigns (Greene, 2011), media coverage (Lawson and McCann, 2005), economic voting (Baker and Greene, 2015; Gomez and Wilson, 2006), and issue voting (Boas and Smith, 2015 . Carlin, Singer and Zechmeister, 2015, Mainwaring, Torcal and Somma, 2015). In general, the evidence shows an important effect of partisan loyalties among those who identify with a political party. Since many voters lack strong partisan attachments however, both electoral campaigns and media coverage have an important impact on voters' electoral decisions (Greene, 2011, Lawson and McCann, 2005).

In a particularly creative study, Lawson et al. assess the role of candidate attractiveness in electoral success in Mexico and Brazil (Lawson et al. 2010). Subjects from the U.S. and India ranked candidates in these elections based on appearance alone, and these rankings were highly predictive of the actual election outcomes. Interestingly, race, determined through a robust coding exercise, was not a significant predictor of success. One possible explanation for this null finding is that the sample of candidate images may not have contained sufficient variation 
in racial phenotypes. This potential gap points to an important frontier for experimental research, which our study fills. By exposing actual voters to carefully manipulated candidate images, we can provide sufficient variation in racial phenotypes to isolate their effects, and thus to explore the electoral effects of phenotypic prejudice among Mexicans.

How should we expect racial phenotypes to impact the choices of first generation Mexican immigrants confronted with a set of political candidates competing for their support in a Mexican election? The historical background of the case and the academic literature leave us with contrasting predictions. Migrants who cling to Mexico's dominant racial ideology likely hold stereotypes that favor white or European-looking candidates. But racial phenotypes might also signal politically-linked candidate traits, which migrants could use to infer shared interests. Dominant stereotypes in Mexico link indigenous phenotypes to lower social class. Combined with the fact that first generation migrants overwhelmingly have low socio-economic status, this mechanism would lead migrants to find common interest with and thus support an indigenous-looking candidate. These competing expectations leave us agnostic as to the specific direction of phenotypic bias, and suggest the following hypothesis:

H1: Skin tone and facial features of political candidates will influence candidate support amongst first generation Mexican migrants.

As the previous comments suggest, appearance might influence voting behavior by shaping the way voters perceive political candidates. The literature has highlighted partisanship and ideology as traits that voters are likely to infer based on appearance. In the Mexican context, these traits could have a particularly strong link to appearance because of the existence of strong stereotypes connecting indigenous phenotypes and social class. Survey evidence showing that dark skin tone is predictive of liberal ideology lends further support to a directional hypothesis, which we state as follows:

H2: All else equal, immigrant voters will view darker skinned and more indigenouslooking candidates as ideologically more liberal than lighter skinned, Europeanlooking candidates.

\section{Racial ideology and the role of time}

Societies construct different understandings of race. Most individuals in the U.S. think of themselves as belonging to one of a set of exclusive racial groups, while a smaller number view themselves as mixed-race. By contrast, most Mexicans think of themselves as mestizo, a racial group characterized by biological and cultural intermixing of indigenous and European roots. While Mexican racial ideology may seem inclusive, it was ultimately a tool of elites to subsume indigenous people into the mestizo category by encouraging them to leave behind their cultural traits and traditions (Knight, 1990). In spite of the pretense of racial equality, many negative stereotypes became associated with the indigenous group, such as belonging to a lower social class and being less educated. Contrasting positive stereotypes came to be associated with whites.

The United States has its own complicated history of defining the racial identity of Mexicans within its borders. In 1930, the census bureau added "Mexican" to its 
list of racial categories, but dropped the category after the Mexican government essentially protested that all Mexicans were white. While Mexican respondents used terms such as Mestizo, Mexicano, or la Raza to describe their race, the U.S. effectively ignored this variation by classifying all of these as white (Perlmann and Waters, 2002, p.5).

Relatively little scholarship has focused on the ways first generation migrants might navigate competing racial ideologies as they move from one context to another. Instead, the literature has focused on time spent in the United States as an important factor shaping political attitudes and behaviors. Latino immigrants who have lived longer in the U.S. demonstrate higher civic and electoral participation (Ramakrishnan and Espenshade, 2001; Stoll and Wong, 2007). Mexican immigrants develop stronger identification with a main U.S. party over time (Wong, 2000). This temporal process also depends on immigrants' experience in their countries of origin, particularly in the case of political ideology and participation (Wals, 2013).

As migrants spend more time in the United States and their patterns of political behavior change, might their interaction with racial ideology change as well? Over time, first generation migrants may gradually adopt the dominant racial ideology of the receiving country. In the United States, this would mean developing a stronger preference for whiteness, which leads to the following, our final hypothesis:

H3: Preference for European-looking candidates will increase as migrants spend more time in the U.S.

\section{Methods}

We conducted the experiment as part of the San Diego County Mexican Immigrant Health and Legal Status Survey (SDCMIHLSS) ${ }^{3}$ The purpose of the SDCMIHLSS was to collect representative data from the Mexican-born population of San Diego County. To that aim, a random selection of census blocks was made from two strata. The first, and largest, stratum of blocks was that which had a concentration of foreign-born Mexicans equal to or greater than $20 \%$ according to the census bureau. The second stratum was a random selection from blocks with a lower than $20 \%$ concentration of foreign-born Mexicans. Setting these sampling strata allowed the SDCMIHLSS to focus canvassing on areas of the city likely to produce a greater number of interviews (increasing efficiency), while at the same maintaining broad representativeness of Mexican-born residents of the greater San Diego Area.

Following Marcelli (2014), in each of these strata, the same protocol was adhered to in order to ensure an equal probability of recruitment into the sample for all households. Survey team members knocked on the doors of potential respondents at prescribed times on weekdays and weekends. Attempts to contact each household continued either until a response was registered, or until three attempts had been made. Households with no foreign-born Mexican residents above the age of fifteen were excluded from the sample. In each household recruited into the sample, the foreign-born Mexican whose birthday had occurred most recently was

\footnotetext{
3 A detailed description of the methodology used to build the sampling frame for this study is provided in Marcelli (2014).
} 
selected to be interviewed. After each respondent was recruited, the survey questionnaire was administered, gathering both household and individual-level data. Survey items included demographics and migration history, followed by a section on political participation.

Embedded into each survey questionnaire was a randomized cue which contained the stimulus of our experiment. This cue, which was visible to the enumerator only when she reached the appropriate point in the instrument, instructed the enumerator to present the subject with the stimuli corresponding to the subjects' randomly assigned experimental condition. Surveying continued in this fashion until resources for the project were exhausted, at which point 200 subjects had completed the questionnaire.

\subsection{Experimental Design}

Experimental stimuli appeared in the political participation section of the survey questionnaire. Following five basic questions about their political participation in Mexico, enumerators read respondents the following prompt:

There are going to be elections in the state of Nayarit to elect the governor in 2014. There are three politicians interested in the elections as independents. They want to compete independently of any political party endorsement.

I am going to give you a card with information about these candidates. Please read the information that I'm going to give you. Mark the ballot for the candidate that you would choose if you lived in Nayarit. When you're finished, fold the ballot, put it in the envelope and seal it. I won't know who you voted for. This is confidential information, only to understand your opinions.

After being read the prompt, participants were assigned at random to view one of four laminated cards, each corresponding to a separate experimental condition. Cards were numbered to ensure that enumerators could locate the card corresponding to the appropriate treatment. Randomization occurred outside the presence of both the enumerator and the subject, meaning that subjects were not aware of which portion of the stimulus constituted the experimental cue, and enumerators did not know ahead of time which stimulus the respondent would be exposed to.

All experimental conditions included information about the hypothetical candidates' issue positions, as shown in Figure 1. This information included candidates' names and a summary of their positions on four minor, non-keystone issues in contemporary Mexican politics (i.e., taxes and social spending, the environment, support of cultural and sports associations, and subsidies for farmworkers). Candidates' policy positions were structured so voters could locate the candidates at different positions on a left-right ideological scale, with one candidate located at the center-left, a second candidate at the center, and the third candidate at the center-right of the spectrum. Importantly, all candidates would easily be identified as moderate choices. In order to eliminate the potentially confounding factor of 


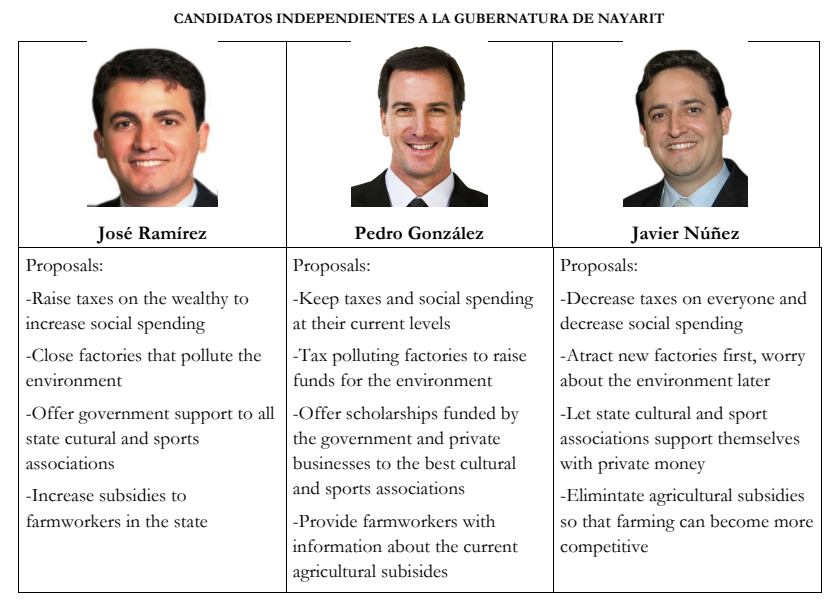

Fig. 1 Ballot shown to subjects, with pictures of the candidates included. Subjects in the control condition saw the same ballot, with the images removed. Subjects in the three treatment conditions saw a ballot with one of the images sets shown in Figure 2. The title of the image reads: Independent candidates for the governorship of Nayarit.

party identification, the stimuli emphasized that candidates were running with no affiliation to any political party ${ }^{4}$

In the control condition, the ballot contained only the policy positions of the candidates and their names, with no associated images. In the remaining three experimental conditions (henceforth, treatment conditions), subjects were shown the same ballot, but with pictures of the hypothetical candidates placed above each name. The image corresponding to the candidates on the left and right of the ballot remained constant across the treatment conditions. The picture of the candidate in the middle of the ballot varied according to the assigned treatment. All three image sets are displayed in Figure 2.

After reviewing the information presented, subjects were provided a "ballot" and a pen to mark their preferred hypothetical candidate. After marking their ballot, subjects folded the ballot and inserted it into an envelope, which the enumerator sealed in the subject's presence.

Our primary motivation for locating this hypothetical voting task in the state of Nayarit was that gubernatorial elections were in fact held in the Mexican state of Nayarit on July 6th, 2014. While it is unlikely that respondents were familiar with the particular details of the election, they may have been aware that elections

4 To our knowledge, no research to date has examined the relationship between party labels and candidates' phenotypic appearance in Mexico. We chose to present independent candidates in order to avoid contaminating the treatment with additional, potentially conflicting signals about party identification. 


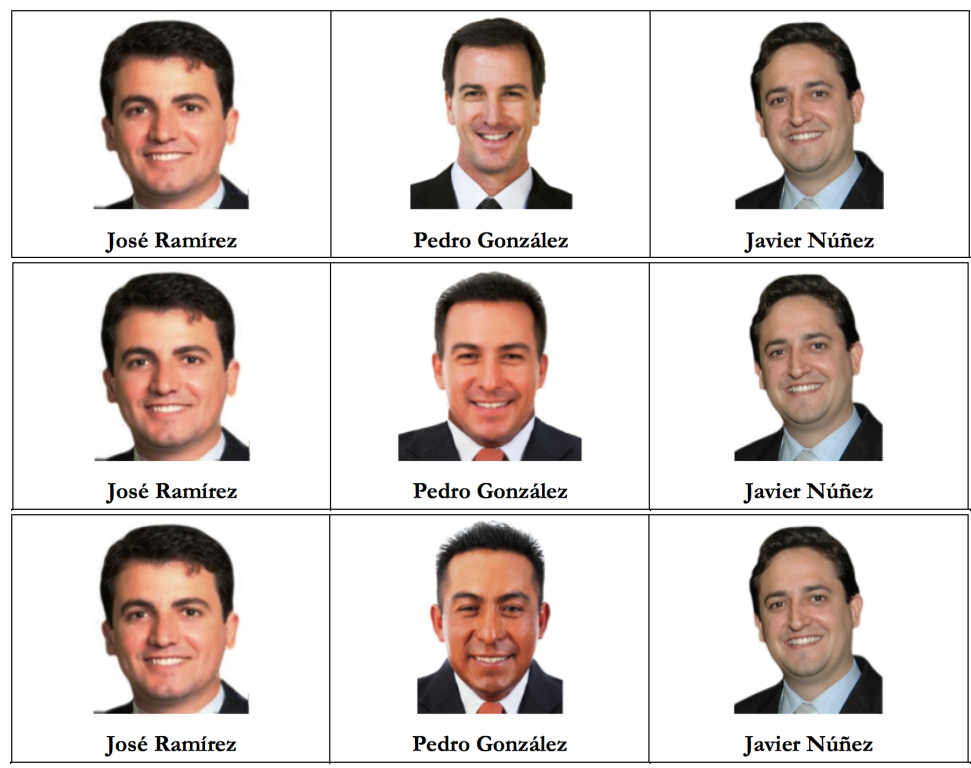

Fig. 2 Pictures shown in the three experimental conditions. The first row shows the phenotypically white candidate, the second row the phenotypically mestizo candidate, and the third row the phenotypically indigenous candidate. The control condition provided the same candidate statements, but no images.

were occurring around the time of this experimental treatment, contributing to the external validity of the experiment $5^{5}$

The images provided in the treatment conditions were designed to carefully manipulate the phenotypic characteristics of the hypothetical candidate in the center of the ballot (henceforth, we refer to the candidate in the center of the ballot as the "target" candidate). In the first treatment condition, the target candidate is depicted as phenotypically white (center photograph, Figure 2 row 1), while in the third condition, the target candidate is phenotypically indigenous (center photograph, Figure 2 row 3). To generate the second condition (center photograph, Figure 2 row 2), we created a candidate photograph by combining the other two photographs using photo morphing software 6 This design replicates that employed in Mexico City by Aguilar (2009), and is informed by previous similar experiments (Terkildsen, 1993, Weaver, 2012, Kam, 2007).

To summarize, all subjects were exposed to the same set of candidate names and policy positions. Subjects in the three treatment conditions were exposed to identical images above the left and right candidates. We experimentally manipulated the image above the target candidate to be either white-, indigenous-, or mestizo-looking.

Assignment to the four experimental conditions was fully randomized, and resulted in between $24 \%$ and $26 \%$ of respondents being assigned to each condition.

\footnotetext{
${ }^{5}$ Nayarit is one of the smallest Mexican states by population, and thus has contributed only a small share to overall Mexico-U.S. migration. While we did not capture respondents' state of origin, it is likely that almost none were natives of Nayarit.

6 http://www.fantamorph.com/
} 
Table A1 attests to the success of randomization and presents the distribution of relevant subject characteristics across experimental conditions. In general, there is good covariate balance across the conditions; no individual test for differences in means indicate imbalance, nor does a likelihood ratio test indicate that multicategory, discrete-choice models that include subject covariates fit better than those which do not (Lin, Green and Coppock, 2017).

\section{Results}

\subsection{Candidate appearance and evaluation}

Of the 200 subjects recruited into SDCMIHLSS, 175 participated in the voting experiment 7 Overall, assigning an indigenous phenotype to a candidate significantly increased the likelihood that subjects would vote for that candidate. In contrast, assigning a candidate an image containing a white, mestizo, or no phenotypic cue (the control condition) did not cause detectable changes in support for the target candidate. When shown an indigenous candidate, $46.5 \%$ of subjects reported a voting preference for that candidate, an increase in support of $11.6 \%$ compared to the white candidate, and an increase of 15.5 and $18.2 \%$ over the control and mestizo candidates, respectively. Figure 3 visualizes this main effect of the experimental treatment on respondents' choice of which candidate to support.

Drawing inference in information manipulation experiments requires some care in establishing appropriate comparison groups. If policy and phenotypic information assigned to subjects had no effect on preferences subjects would select candidates at random; in expectation one third of subjects would identify a preference for the target candidate. One-sample t-tests find no difference in support when subjects were shown no phenotypic information (one sample t-test $P=0.48$ ), a white candidate (one sample t-test $P=0.80$ ), or a mestizo candidate (one sample t-test $P=0.78)$. When shown an indigenous candidate, subjects prefer the target candidate at higher rates than random (one sample t-test $P=0.086$ ).

Support for the indigenous candidate persists in a regression framework. The first column of Table 1 recreates our estimates from the differences in proportions tests. Subjects shown the indigenous target candidate were significantly more likely to vote for the target candidate $(O R=1.91, P=0.0718)$. This significant relationship persists when covariates measuring subjects' age, sex, level of education and years spent in the U.S. are included in the model $(O R=2.33, P=0.066)$.

Thus we find support for our first hypothesis, that racial appearance will influence candidate support among first generation Mexican immigrants. More specifically, our findings suggest a limited role for the dominant Mexican racial ideology, which would predict a general preference for whiteness. Instead, the finding that voters prefer the indigenous candidate accords with a model in which racial stereotypes cue political traits, which are then used to infer shared interests. First generation immigrants, who are predominantly working class, may be supporting the candidate whose phenotype suggests shared interests on economic policy.

Appearance also impacted respondents' views about the non-racial traits of the candidates. After reviewing the ballot, respondents were asked to assess the

\footnotetext{
7 Participants were informed, at the time of recruitment, that they could choose not to answer any survey item.
} 


\section{Rate of choosing target candidate}

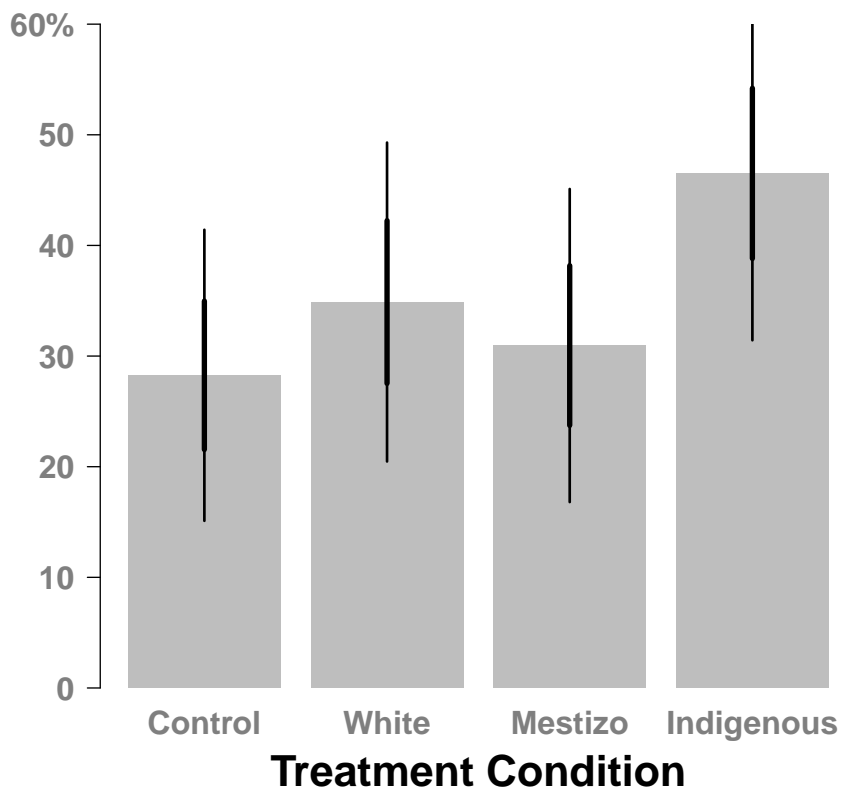

Fig. 3 Mean rate of voting for the target candidate, by treatment condition. Thick bars are standard errors of the mean, thin bars are 1.96 times these standard errors.

target candidate on a five-point ideology scale, with one being the most liberal and five being the most conservative. Figure 4 displays the results of this task by experimental condition. In the control condition, in which no image is provided, respondents evaluated the candidate as a being just right of ideological center. In the white and mestizo conditions, however, respondents viewed the candidates as significantly more conservative, moving more than an entire point to the right along the scale ${ }^{8}$ In contrast, the indigenous candidate was not viewed as significantly more conservative than the control.

These results provide support for our second hypothesis. Immigrants may be relying on stereotypes that link race and social class, and using that stereotype to infer candidate ideology. More generally, this evidence supports our claim that racial phenotypes change electoral preference through a signal of shared economic interests.

Finally, we point to evidence that our respondents had sufficient familiarity with the context to be able to reliably express their preferences in a hypothetical Mexican election. In particular, participants were able to reliably order the ideological positions of the main Mexican political parties, signaling that although they were residing in the US at the time, they were familiar with the broad contours of Mexican politics. As we report in Figure A1 in the appendix, the center of mass of the PRD, PAN, and PRI follow a plausible left to right alignment.

\footnotetext{
8 The differences between these two conditions and the control group are also significant in a regression including the same controls that appear in Table 1 (results not shown).
} 
Table 1 Logit regression of experimental treatment. The dependent variable is subjects' registered preference for the target candidate. The base category for the experimental treatment conditions is the control condition.

\begin{tabular}{|c|c|c|c|c|}
\hline & \multicolumn{4}{|c|}{ Dependent variable: } \\
\hline & \multicolumn{4}{|c|}{ Vote for target candidate } \\
\hline & $(1)$ & $(2)$ & (3) & $(4)$ \\
\hline White candidate & $\begin{array}{c}0.307 \\
(0.458)\end{array}$ & $\begin{array}{c}0.184 \\
(0.497)\end{array}$ & $\begin{array}{c}0.168 \\
(0.500)\end{array}$ & $\begin{array}{c}-2.949^{* *} \\
(1.471)\end{array}$ \\
\hline Mestizo candidate & $\begin{array}{c}0.129 \\
(0.468)\end{array}$ & $\begin{array}{r}-0.175 \\
(0.493)\end{array}$ & $\begin{array}{c}-0.322 \\
(0.505)\end{array}$ & $\begin{array}{r}-0.377 \\
(1.065)\end{array}$ \\
\hline Indigenous candidate & $\begin{array}{c}0.792^{*} \\
(0.448)\end{array}$ & $\begin{array}{c}0.849^{*} \\
(0.462)\end{array}$ & $\begin{array}{c}0.832^{*} \\
(0.465)\end{array}$ & $\begin{array}{c}1.614 \\
(1.080)\end{array}$ \\
\hline Age & & $\begin{array}{c}0.010 \\
(0.013)\end{array}$ & $\begin{array}{c}0.016 \\
(0.017)\end{array}$ & $\begin{array}{c}0.014 \\
(0.018)\end{array}$ \\
\hline Sex & & $\begin{array}{c}0.611 \\
(0.378)\end{array}$ & $\begin{array}{c}0.608 \\
(0.381)\end{array}$ & $\begin{array}{c}0.497 \\
(0.399)\end{array}$ \\
\hline Education & & $\begin{array}{c}0.050 \\
(0.046)\end{array}$ & $\begin{array}{c}0.057 \\
(0.047)\end{array}$ & $\begin{array}{c}0.046 \\
(0.049)\end{array}$ \\
\hline Years in U.S. & & & $\begin{array}{c}-0.009 \\
(0.021)\end{array}$ & $\begin{array}{c}-0.022 \\
(0.036)\end{array}$ \\
\hline White cand*Years in U.S. & & & & $\begin{array}{c}0.125^{* *} \\
(0.055)\end{array}$ \\
\hline Mestizo cand*Years in U.S. & & & & $\begin{array}{c}0.004 \\
(0.045)\end{array}$ \\
\hline Indigenous cand ${ }^{*}$ Years in U.S. & & & & $\begin{array}{c}-0.034 \\
(0.045)\end{array}$ \\
\hline Constant & $\begin{array}{c}-0.932^{* * *} \\
(0.327)\end{array}$ & $\begin{array}{c}-2.719^{* *} \\
(1.065)\end{array}$ & $\begin{array}{c}-2.771^{* *} \\
(1.082)\end{array}$ & $\begin{array}{c}-2.116^{*} \\
(1.217)\end{array}$ \\
\hline Observations & 174 & 166 & 164 & 164 \\
\hline Log Likelihood & -110.880 & -101.910 & -100.100 & -94.427 \\
\hline Akaike Inf. Crit. & 229.770 & 217.830 & 216.190 & 210.850 \\
\hline
\end{tabular}

4.2 The dynamic effect of phenotype

We now turn to our third and final hypothesis, which focuses on how the effect of phenotype on candidate evaluation changes over time. Here, we leverage the variation between individuals within our sample of first-generation Mexican immigrants. Because our data are cross-sectional, we cannot adjudicate how increasing tenure in the U.S. causes changes in candidate preferences within an individual. However, we present evidence that the association between individuals' tenure within the U.S. and candidate preference is not driven by omitted variables. 


\section{Respondent estimate of candidate ideology}

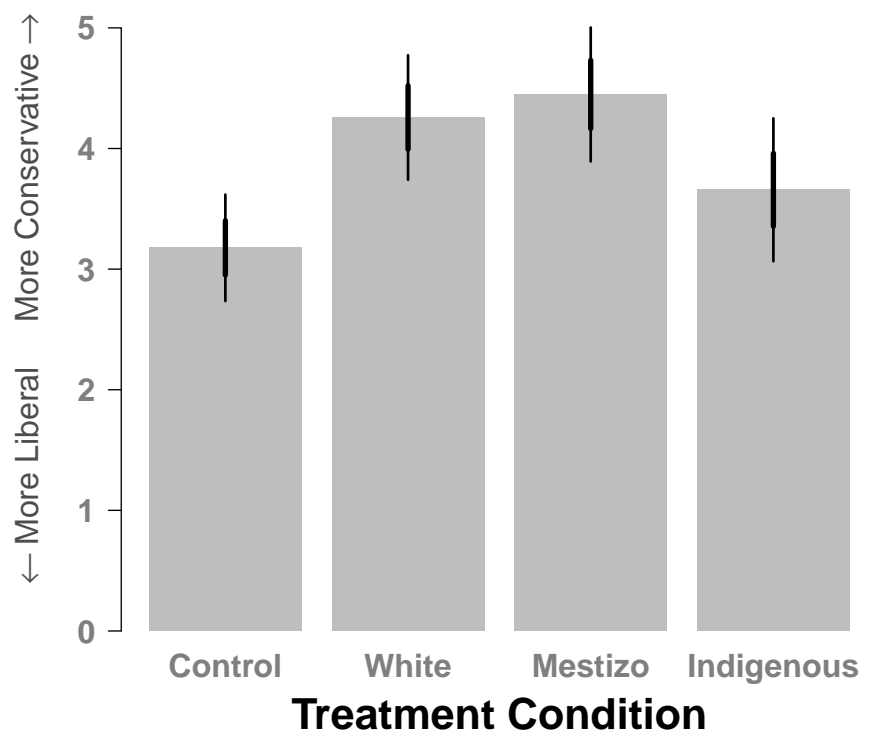

Fig. 4 Respondent evaluation of hypothetical candidates on five-point ideological scale. Thick bars are standard errors and thin bars are 1.96 times the standard errors.

Our third hypothesis predicts that the longer an immigrant lives in the U.S., the less decisive phenotype will be in influencing their evaluation of candidates. To test the hypothesis, we estimate regression models that interact the experimental stimulus with the number of years a subject has lived in the U.S. (model results appear in columns 3 and 4 of Table 1.

Both models demonstrate a statistically significant and substantively important change in the relationship as subjects live more years in the U.S. When subjects had spent little time in the United States, they were less likely to support the target candidate when he was white than when phenotypic information was not included $(O R=0.05, p=0.045)$. As we plot in Figure 5, as time in the United States increases, so does preference for the white candidate vis-à-vis the control condition $(O R=1.13, p=0.024)$. In contrast, if assigned to the indigenous candidate condition, subjects' preference for the target candidate decreases with increased time in the U.S. $(O R=0.96, p=0.45)$.

Indeed, these models predict that subjects who lived in the U.S. for about 20 years or more supported the white candidate at the same rate as the control candidate ${ }^{9}$ The same model estimates that subjects who had lived in the U.S. for more than 25 years were one standard error more likely to support the whitelooking candidate than the control candidate.

Among those shown an indigenous-looking candidate the converse relationship held. Subjects assigned to the indigenous condition who had lived in the U.S. fewer

\footnotetext{
9 More than $60 \%$ of this sample had lived in the U.S. more than 20 years.
} 


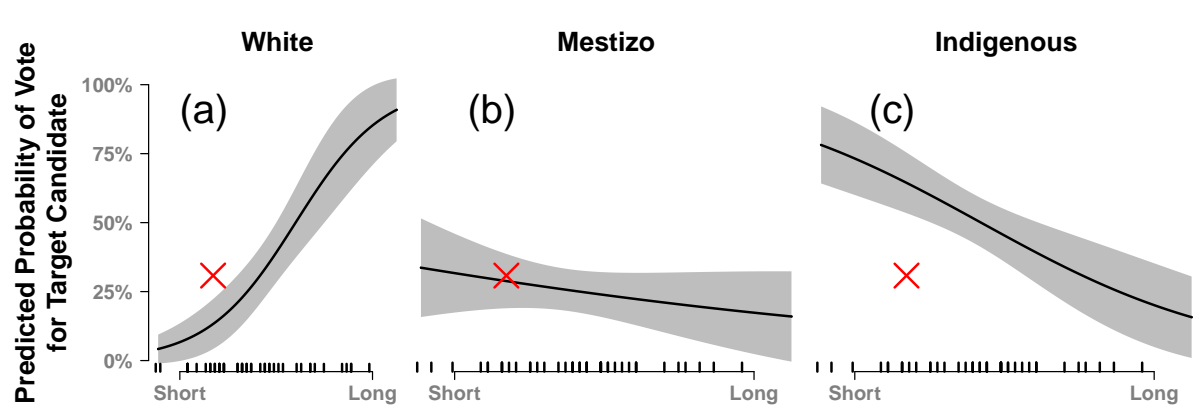

Fig. 5 Panel (a) plots the conditional relationship between voter preference for the white candidate (vs. the control candidate) as a function of years living in the U.S. Increased time in the U.S. is associated with an increased preference for the phenotypically white candidate. Panel (b) plots the conditional relationship for the mestizo candidate (vs. the control candidate) as a function of years living in the U.S. There is no conditional relationship. Panel (c) plots the conditional relationship between voter preference for the indigenous candidate (vs. the control candidate) as a function of years in the U.S. Increased time in the U.S. is associated with a decreased preference for the phenotypically indigenous candidate. In all three panels the error envelope is $\pm 1 \mathrm{SE}$. In this sample the minimum number of years in the U.S. is 1 year and the maximum number of years is 54 . The rug plot shows data coverage on the "Years in the U.S." variable. In all windows the "X" marks the predicted level of support for the target candidate in the control condition for a respondent who has lived in the U.S. for the mean number of years.

than 37 years more frequently chose the target candidate than subjects who had been assigned to the control condition. While few subjets manifested a preference against the indigenous-looking candidate, the strength of subjects' preference for that candidate wanes through increasing tenure in the U.S.

For ease of interpretation, Figure 5 visualizes the results of these estimates. Here, we hold all covariates at constant levels ${ }^{10}$ and vary experimental condition across the plot windows - on the left are subjects shown a white candidate, in the center subjects shown a mestizo candidate, and on the right subjects shown an indigenous candidate. Within each window we continuously vary how long subjects in that condition had resided in the U.S, from the minimum reported tenure (1 year) to the maximum reported tenure (54 years). In each plot, an "X" plots the support for the target candidate in the control (no images) condition at the mean number of years our subject pool had lived in the U.S.

Our results provide support for Hypothesis 3. The overall pattern of evidence is that, at the time closest to immigrants' arrival in the United States, there is a strong preference for the indigenous phenotype, and a penalty assessed to the white candidate. As immigrants spend more time in the United States, these preferences overlap, and ultimately cross. Among those with the longest tenure in the United States, the bonus for indigenous appearance has largely disappeared, as well as the penalty for appearing white.

As a caveat, we note that the results related to our third hypothesis are drawn from cross-sectional data, but are intended to answer a question about changes over time. This approach has the disadvantage that the findings may be driven by compositional features in the study sample that would not reflect the underlying

10 Age, Sex and Education were all set to their median values. 
individual dynamics. In other words, it could be that the migrants in our sample who have lived for longer in the United States systematically differ from the newer migrants in the sample in a way that does not entirely reflect changes that those migrants underwent during their time in the U.S. While we cannot discard this possibility entirely, we are able to rule out two primary concerns - that ideological positions or phenotypic profiles differ between recent migrants and those who have lived longer in the U.S.

While we acknowledge that it is possible that substantively important change in subjects' preferences could have led to changes in candidate evaluation, data gathered in the study suggest this is not the case. As a first order test, we consider whether immigrants with a longer tenure in the United States are also more ideologically conservative. Figure A1 demonstrates that there is no difference between conservatives and liberals in the number of years they have lived in the U.S. (two-sided t-test, $p=0.15$ ) ${ }^{1}$

\section{Discussion}

As diaspora communities continue to grow around the globe, the question of how immigrant voters evaluate candidates competing in their countries of origin becomes increasingly important. Our paper contributes to this field of inquiry by examining first-generation Mexican immigrants' phenotypic attitudes towards members of their own ethnic group. We conclude that racial appearance matters for these immigrant voters in country-of-origin electoral contexts with low levels of information. While some research treats Latinos as a unified racial group, our study shows they differentiate each other in terms of their phenotypic appearance, in spite of being members of the same ethnic group, sharing similar traditions and origins.

In particular, we find that first generation immigrants are more supportive of a phenotypically indigenous candidate. This finding is counterintuitive, considering that the dominant racial ideology in Mexico associates favorable stereotypes with white candidates. In our interpretation, migrants are instead being driven by a stereotype that associates indigenous phenotype with lower social class. This stereotype is signaling a shared economic interest for first generation immigrants, who generally have low socio-economic status.

We also find that phenotypes cue ideological differences between candidates. Specifically, European and Mestizo appearance led respondents to evaluate candidates as more conservative, while Indigenous appearance did not. This finding accords with research in Mexico showing that voters think of white candidates as more conservative (Aguilar, 2011). A plausible mechanism for this effect that comports with our argument is that appearance signals shared interests through a perceived correlation between phenotype and social class.

\footnotetext{
11 In regression results, not shown but included in the online data and analysis file, we also show that subjects in the control condition (those who saw no candidate image) demonstrated no statistically significant relationship between time in the U.S. and preference for the target candidate. This further reinforces our contention that the findings in support of our Hypothesis 3 are driven by subjects' reactions to the experimental cue, and not by differences in the political views of more recent and more experienced migrants in our sample.
} 
The precise dynamics of the phenotypic bias we discover remain unclear. Given the strength of the association between phenotype and social class in Mexico, racial appearance may automatically trigger the social class and ideological position of the candidates in voters' minds (Devine, 1989, Pérez, 2016, Winter, 2010; Mendelberg, 2001). The design of our study does not allow us to differentiate between automatic and more conscious process while evaluating the electoral candidates. Future research should investigate the automatic effects of the stereotypes associated to different phenotypes.

Our research underscores that phenotypes matter for first generation immigrants, and that their effect varies over time. Specifically, we find that the preference for indigenous features gives way to a preference for whiteness as migrants' tenure in the U.S. increases. We interpret this as evidence that first generation immigrants gradually come to adopt facets of the dominant racial ideology, which associate positive stereotypes with white phenotypes.

Research on the political effects of racial phenotypes in Latin America generally and Mexico specifically is still nascent. Most existing scholarship is based on observational data (Canache et al., 2014; Lawson et al., 2010; Flores and Telles, 2012 , among others). Only a few studies have used experimental methods to draw inferences with stronger internal validity about the effects of racial appearance in the context (Aguilar et al., 2015, Aguilar, 2009, Bueno and Dunning, 2017). Our article contributes to this developing line of research by showing how, among Mexican immigrants in the United States, racial differences may have profound impacts on the evaluation of and support for electoral candidates.

Acknowledgements In addition to the funders mentioned above, we also acknowledge the support of the Center for Comparative Immigration Studies and the Center for U.S.-Mexican Studies. The project could not have been carried out without the efforts of Enrico Marcelli, Allison Van Vooren, Wayne Cornelius, and all of the students who participated in the 20132014 round of the Mexican Migration Field Research Program. We thank Seth Hill, Ricardo Ramirez, Tom Wong, Will Terry, and seminar participants at the 2014 MPSA, APSA, and PRIEC meetings for helpful comments. The standard disclaimer applies.

\section{References}

Adida, Claire L., Lauren D. Davenport and Gwyneth McClendon. 2016. "Ethnic cueing across minorities: a survey experiment on candidate evaluation in the United States." Public Opinion Quarterly 4(80):815-836.

Aguilar, Rosario. 2009. The Political Consequences of Prejudice among Mexicans and Mexican Americans Thesis University of Michigan.

Aguilar, Rosario. 2011. "Social and Political Consequences of Stereotypes Related to Racial Phenotypes in Mexico." CIDE Working Paper, DTEP-230.

Aguilar, Rosario. 2015. "The Effect of Context on the Expression of Prejudice: Electoral Behavior in the U.S. and Mexico." CIDE.

Aguilar, Rosario, Saul Cunow, Scott Desposato and Leonardo Barone. 2015. "Ballot Structure, Candidate Race, and Vote Choice in Brazil." Latin American Research Review 50(3):175-202.

Allport, Gordon. 1954. The Nature of Prejudice. Cambridge: Addison-Wesley. 
Ashmore, Richard D. and F. K. del Boca. 1981. Sex Stereotypes and Implicit Personality Theory. In Cognitive Processes in Stereotyping and Intergroup Behavior, ed. D. L. Hamilton. Erlbaum.

Baker, Andy and Kenneth F Greene. 2015. Positional issue voting in Latin America. In The Latin American Voter: Pursuing Representation and Accountability in Challenging Contexts, ed. Ryan E. Carlin, Matthew M. Singer and Elizabeth J. Zechmeister. University of Michigan Press.

Barreto, Matt A. 2005. "Latino immigrants at the polls: Foreign-born voter turnout in the 2002 election." Political Research Quarterly 58(1):79-86.

Barreto, Matt A. 2007. "iSí Se Puede! Latino candidates and the mobilization of Latino voters." American Political Science Review 101(3):425-441.

Berinsky, Adam J and Tali Mendelberg. 2005. "The indirect effects of discredited stereotypes in judgments of Jewish leaders." American Journal of Political Science 49(4):845-864.

Boas, Taylor and Amy Erica Smith. 2015. Religion and the Latin American Voter. In The Latin American Voter: Pursuing Representation and Accountability in Challenging Contexts, ed. Ryan E. Carlin, Matthew M. Singer and Elizabeth J. Zechmeister. University of Michigan Press.

Bueno, Natália S and Thad Dunning. 2017. "Race, resources, and representation: evidence from Brazilian politicians." World Politics 69(2):327-365.

Callghan, Karen and Nayda Terkildsen. 2002. "Understanding the role of race in candidate evaluation." Political Decision Making, Deliberation, and Participation 6:51-95.

Canache, Damarys, Matthew Hayes, Jeffery J Mondak and Mitchell A Seligson. 2014. "Determinants of perceived skin-color discrimination in Latin America." The Journal of Politics 76(2):506-520.

Carlin, Ryan E., Matthew M. Singer and Elizabeth J. Zechmeister. 2015. Conclusion. In The Latin American Voter: Pursuing Representation and Accountability in Challenging Contexts, ed. Ryan E. Carlin, Matthew M. Singer and Elizabeth J. Zechmeister. University of Michigan Press.

Colleau, Sophie M, Kevin Glynn, Steven Lybrand, Richard M Merelman, Paula Mohan and James E Wall. 1990. "Symbolic racism in candidate evaluation: An experiment." Political Behavior 12(4):385-402.

Devine, Patricia G. 1989. "Stereotypes and prejudice: Their automatic and controlled components." Journal of personality and social psychology 56(1):5.

Domínguez, Jorge I and Chappell H Lawson. 2004. Mexico's Pivotal Democratic Election: Candidates, Voters, and the Presidential Campaign of 2000. Stanford University Press.

Domínguez, Jorge I, Chappell H Lawson and Alejandro Moreno. 2009. Consolidating Mexico's democracy: the 2006 presidential campaign in comparative perspective. Johns Hopkins Univ Pr.

Doremus, Anne. 2001. "Indigenism, Mestizaje, and National Identity in Mexico during the 1940s and the 1950s." Mexican Studies/Estudios Mexicanos 17(2):375402.

Fiske, Susan T. and S. E. Taylor. 1984. Social Cognition. Reading, Mass: AddisonWesley Pub. Co.

Flores, René and Edward Telles. 2012. "Social Stratification in Mexico: Disentangling Color, Ethnicity, and Class." American Sociological Review 77(3):486-494. 
Gomez, Brad T and J Matthew Wilson. 2006. "Cognitive heterogeneity and economic voting: A comparative analysis of four democratic electorates." American Journal of Political Science 50(1):127-145.

Graves, Scott and Jongho Lee. 2000. "Ethnic underpinnings of voting preference: Latinos and the 1996 US senate election in Texas." Social Science Quarterly pp. 226-236.

Greene, Kenneth F. 2011. "Campaign Persuasion and Nascent Partisanship in Mexico's New Democracy." American Journal of Political Science 55(2):398-416.

Highton, Benjamin. 2004. "White voters and African American candidates for congress." Political Behavior 26(1):1-25.

Juenke, Eric Gonzalez. 2014. "Ignorance Is Bias: The Effect of Latino Losers on Models of Latino Representation." American Journal of Political Science 58(3):593-603.

Kam, Cindy D. 2007. "Implicit Attitudes, Explicit Choices: When Subliminal Priming Predicts Candidate Preferences." Political Behavior 29:343-367.

Karlins, Marvin, Thomas L Coffman and Gary Walters. 1969. "On the fading of social stereotypes: Studies in three generations of college students." Journal of personality and social psychology 13(1):1.

Kinder, Donald R. 1986. "Presidential character revisited." Political cognition 19.

Klesner, Joseph L. 2002. "Presidential and congressional elections in Mexico, July 2000." Electoral Studies 21(1):140-147.

Klesner, Joseph L. 2005. "Electoral competition and the new party system in Mexico." Latin American Politics and Society 47(2):103-142.

Knight, Alan. 1990. Racism, Revolution and Indigenismo: Mexico, 1910-1940. In The Idea of Race in Latin America, 1870-1940. Austin: University of Texas Press.

Lawson, Chappell, Gabriel S Lenz, Andy Baker and Michael Myers. 2010. "Looking like a winner: Candidate appearance and electoral success in new democracies." World Politics 62(4):561-593.

Lawson, Chappell and James A McCann. 2005. "Television news, Mexico's 2000 elections and media effects in emerging democracies." British Journal of Political Science 35(1):1-30.

Lerman, Amy E, Katherine T McCabe and Meredith L Sadin. 2015. "Political ideology, skin tone, and the psychology of candidate evaluations." Public Opinion Quarterly 79(1):53-90.

Lin, Winston, Donald P. Green and Alexander Coppock. 2017. "Standard Operating Procedures for Don Green's Lab at Columbia." https://github.com/ acoppock/Green-Lab-SOP. Accessed: 27 October 2017.

Maddox, Keith B. 2004. "Perspectives on Racial Phenotypicality Bias." Personality and Social Psychology Review 8:383-401.

Mainwaring, Scott, Mariano Torcal and Nicolas Somma. 2015. The Left and the Mobilization of Class Voting in Latin America. In The Latin American Voter: Pursuing Representation and Accountability in Challenging Contexts, ed. Ryan E. Carlin, Matthew M. Singer and Elizabeth J. Zechmeister. University of Michigan Press.

Manzano, Sylvia and Gabriel R Sanchez. 2010. "Take one for the team? Limits of shared ethnicity and candidate preferences." Political Research Quarterly 63(3):568-580.

Marcelli, Enrico A. 2014. Community-Based Migrant Household Probability Sampling. In Migration and Health Research Methodologies: A Handbook for the Study 
of Migrant Populations, ed. Marc Schenker, Xochitl Castaneda and Alfonso Rodrizuez-Lainz. University of California Press.

McConnaughy, Corrine, White, David Leal and Jason Casellas. 2010. "A Latino on the Ballot: Explaining Coethnic Voting Among Latinos and the Response of White Americans." Journal of Politics 72(4):1199-1211.

Mendelberg, Tali. 2001. The race card: Campaign strategy, implicit messages, and the norm of equality. Princeton University Press.

Moreno, Alejandro. 2009. La decisión electoral: votantes, partidos y democracia, México. Miguel Ángel Porrúa.

Moskowitz, David and Patrick Stroh. 1994. "Psychological sources of electoral racism." Political Psychology pp. 307-329.

Pérez, Efrén O. 2016. Unspoken Politics: Implicit Attitudes and Political Thinking. Cambridge University Press.

Perlmann, Joel and Mary C Waters. 2002. The new race question: How the census counts multiracial individuals. Russell Sage Foundation.

Popkin, Samuel L. 1991. "The reasoning voter".

Ramakrishnan, S Karthick and Thomas J Espenshade. 2001. "Immigrant incorporation and political participation in the United States." International Migration Review 35(3):870-909.

Reeves, Keith. 1997. Voting Hopes or Fears?: White Voters, Black Candidates, and Racial Politics in America. Oxford University Press.

Sanbonmatsu, Kira. 2002. "Gender stereotypes and vote choice." American Journal of Political Science pp. 20-34.

Sears, David O, Jack Citrin and Richard Kosterman. 1987. "Jesse Jackson and the southern white electorate in 1984." Blacks in Southern politics pp. 209-25.

Sigelman, Carol K, Lee Sigelman, Barbara J Walkosz and Michael Nitz. 1995. "Black candidates, white voters: Understanding racial bias in political perceptions." American Journal of Political Science pp. 243-265.

Smith, Edward E and Douglas L Medin. 1981. Categories and concepts. Harvard University Press Cambridge, MA.

Stoll, Michael A and Janelle S Wong. 2007. "Immigration and civic participation in a multiracial and multiethnic context." International Migration Review 41(4):880908.

Sue, Christina A and Tanya Golash-Boza. 2013. "It was only a joke": How racial humour fuels colour-blind ideologies in Mexico and Peru." Ethnic and Racial Studies 36(10):1582-1598.

Tate, Katherine. 1994. From protest to politics: The new black voters in American elections. Harvard University Press.

Terkildsen, Nayda. 1993. "When white voters evaluate black candidates: The processing implications of candidate skin color, prejudice, and self-monitoring." American Journal of Political Science pp. 1032-1053.

Villarreal, Andrés. 2010. "Stratification by Skin Color in Contemporary Mexico." American Sociological Review 75(5):652-678.

Von Hippel, William, Denise Sekaquaptewa and Patrick Vargas. 1997. "The linguistic intergroup bias as an implicit indicator of prejudice." Journal of Experimental Social Psychology 33(5):490-509.

Wals, Sergio C. 2013. "Made in the USA? Immigrants' imported ideology and political engagement." Electoral Studies 32(4):756-767. 
Weaver, Vesla. 2012. "The Electoral Consequences of Skin Color: The "Hidden" Side of Race in Politics." Political Behavior 34(1):159-192.

Winter, Nicholas. 2010. "Masculine Republicans and feminine Democrats: Gender and Americans' explicit and implicit images of the political parties." Political Behavior 32(4):587-618.

Wong, Janelle S. 2000. "The effects of age and political exposure on the development of party identification among Asian American and Latino immigrants in the United States." Political Behavior 22(4):341-371. 


\section{A Appendix}

A.1 Randomization check

In this randomization check, we examine whether there are differences in the observable characteristics of our respondents, grouped by treatment assignment category. If such differences existed, it would be evidence that there was a systematic breakdown of our randomization and assignment regime. No such differences exist, neither as reported here in Table A1, nor in a likelihood ratio test (not reported) in our analysis.

Table A1 Balance on observables. Variable mean reported with standard errors in parentheses. p-value of two-tailed t-test, null hypothesis of no difference between control and corresponding treatment in square brackets.

\begin{tabular}{lllll}
\hline \hline & Control & White & Mestizo & Indigenous \\
\hline Age & 40.78 & 39.72 & 41.97 & 44.55 \\
& $(15.43)$ & $(14.56)$ & $(15.92)$ & $(15.77)$ \\
Proportion Female & 0.70 & {$[0.73]$} & {$[0.71]$} & {$[0.24]$} \\
& $(0.46)$ & $(0.51$ & 0.71 & 0.55 \\
Years in US & & {$[0.06]$} & $(0.45)$ & $(0.50)$ \\
& 22.34 & 23.64 & 21.83 & {$[0.12]$} \\
Education & $(11.64)$ & $(10.30)$ & $(12.22)$ & $(12.56)$ \\
& & {$[0.57]$} & {$[0.84]$} & {$[0.27]$} \\
& 7.04 & 8.04 & 7.81 & 6.10 \\
& $(3.93)$ & $(4.26)$ & $(4.09)$ & $(4.00)$ \\
\hline \hline
\end{tabular}


A.2 Ideology through time

A possible concern is that the primary driver of our results for differential evaluation of candidate ideology through time might result from different ideology profiles being present among our sample of Mexican-born residents of San Diego County. There is no evidence to suggest an association between SDCMIHLSS participant's time in the US and reported ideology. As we report in Figure A1 neither a split by binned ideology (in the left panel) nor a full recover of the data (in the right panel) give any support to such a theory.
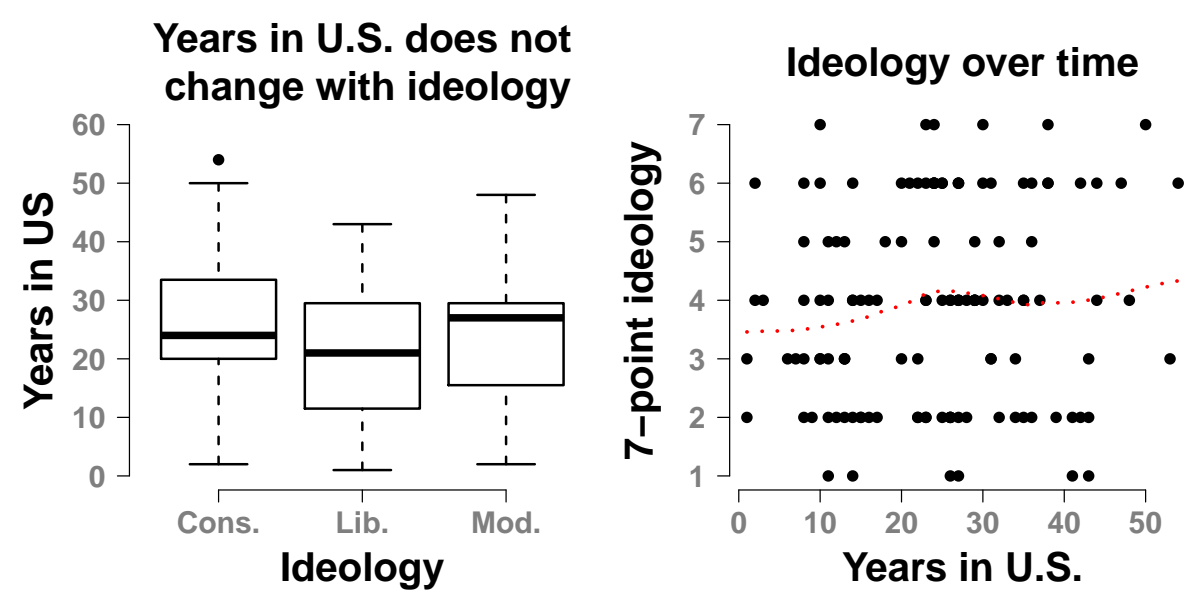

Fig. A1 There is no effect of time in U.S. on ideology. The left panel coarsens ideology and bins. The right panel reports all the data, and fits a moving smoothed moving average estimate of 7-point ideology across number of years in the U.S. 
A.3 Knowledge of party systems in Mexico

\section{Respondents' assesments of} candidate ideology

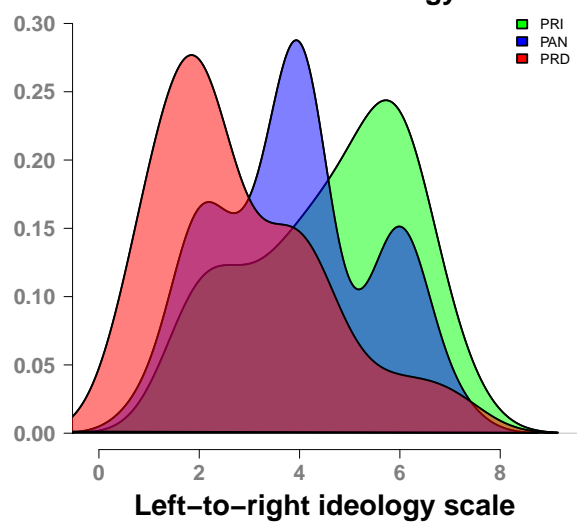

Fig. A1 Density plots show respondents' assessments of the target candidate's ideology. Values are grouped by respondents' assessment of the political party that the target candidate would most likely be affiliated with.

Each of the overlaid density plots shows the distribution of ideology values attributed to the candidate. The values are grouped according to the respondent's answer to the question, "If [the target candidate] were affiliated with a political party, which party do you think it would be?" In other words, the values plotted in red (medium shade) show how respondents who presumed the candidate belonged to the left-leaning PRD described the candidate's ideology. The figure shows that, while there is substantial variation in the attributed ideology of the candidate, respondents are generally reliable in classifying the main political parties of Mexico along the ideological spectrum. 